\title{
UNDERWATER CALIBRATION OF DOME PORT PRESSURE HOUSINGS
}

\author{
E. Nocerino ${ }^{\text {a }}$,F. Menna ${ }^{\text {a }}$, F. Fassi ${ }^{\text {b }}$, F. Remondino ${ }^{\text {a }}$ \\ a 3D Optical Metrology unit, Bruno Kessler Foundation (FBK), via Sommarive 18, Trento 38123, Italy \\ Email: (nocerino, fmenna, remondino)@fbk.eu \\ b Politecnico di Milano, ABC Dep. 3DSurvey Group, via Ponzio 31, Milano 20133, Italy - Email: francesco.fassi@ polimi.it
}

\section{Commission V, WG 1}

KEY WORDS: Underwater, Photogrammetry, Camera calibration, Decentring distortion

\begin{abstract}
:
Underwater photogrammetry using consumer grade photographic equipment can be feasible for different applications, e.g. archaeology, biology, industrial inspections, etc. The use of a camera underwater can be very different from its terrestrial use due to the optical phenomena involved. The presence of the water and camera pressure housing in front of the camera act as additional optical elements. Spherical dome ports are difficult to manufacture and consequently expensive but at the same time they are the most useful for underwater photogrammetry as they keep the main geometric characteristics of the lens unchanged. Nevertheless, the manufacturing and alignment of dome port pressure housing components can be the source of unexpected changes of radial and decentring distortion, source of systematic errors that can influence the final 3D measurements. The paper provides a brief introduction of underwater optical phenomena involved in underwater photography, then presents the main differences between flat and dome ports to finally discuss the effect of manufacturing on 3D measurements in two case studies.
\end{abstract}

\section{INTRODUCTION}

As in case of more traditional aerial and terrestrial photogrammetry, also in the field of underwater photogrammetry advances and progresses have gone hand in hand with improvements in photography. Nowadays the number of demanding applications is constantly growing mainly thanks to technical achievements in diving apparatus, photographic equipment and underwater manned and unmanned vehicles. Stating the peculiarities of a hostile environment such as the underwater world, probably even more then in air, an insight of the basic principles of underwater photography and equipment is fundamental for a successful approach to underwater photogrammetry. Testing and investigating the geometrical characteristics of underwater consumer grade photographic equipment when used for photogrammetric applications would be advisable if accuracy and reliability matter. Professional results always rely on the control of all the technical parameters involved. The knowledge about photographic equipment and its behaviour in different conditions is the first step to be investigated.
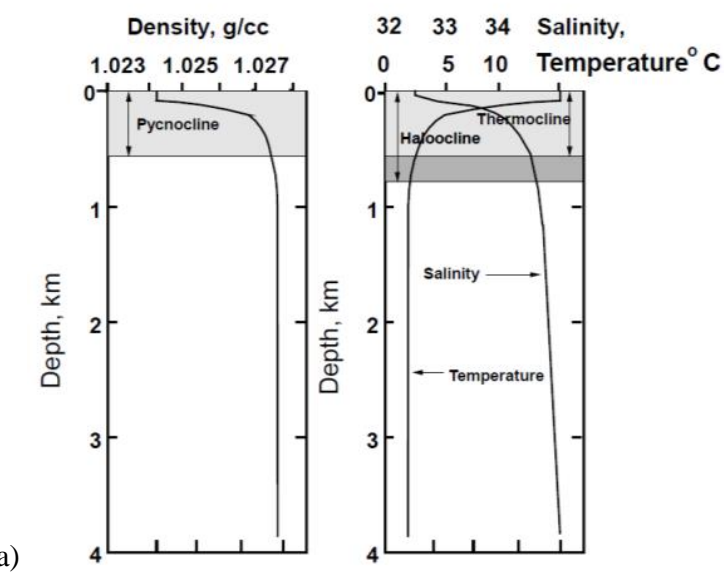

b)

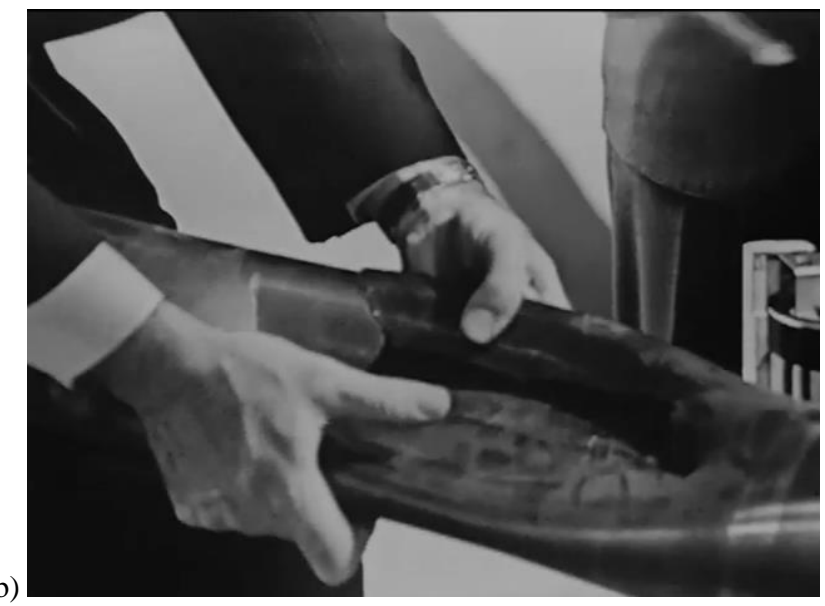

Figure 1. (a) Water density, salinity and temperature variation with depth (Ocean Stanford Edu). (b) Effect of pressure at high depth: Steel waterproof camera housing collapsed at a depth of about $6000 \mathrm{~m}$ (frame extracted from EDC).
Moving from this consideration, in the first part of this contribution the main physical properties of water are explained in relation to how they affect underwater photography. Then, a brief history on the evolution on underwater camera equipment is presented, highlighting the difference between the two types of lens ports (flat and spherical). The study is then focused on the geometric and optic characterization of a consumer grade pressure housing with a dome port (NiMAR NI303D and NI320), in which a DSLR Nikon D300 with a Nikkor $24 \mathrm{~mm}$ is mounted. Both simulations and tests underwater are carried out and described. The theoretical part of the research study is conducted using freely available WinLens 3D Basic and Predesigner and software application by Qioptiq Photonics and Matlab scripts developed had-hoc. Underwater tests are performed both on a small archaeological find and an elongated object to analyse different underwater camera calibration procedures. In the conclusion, specific aspects which deal with photogrammetric acquisitions are considered and practical suggestions provided. 

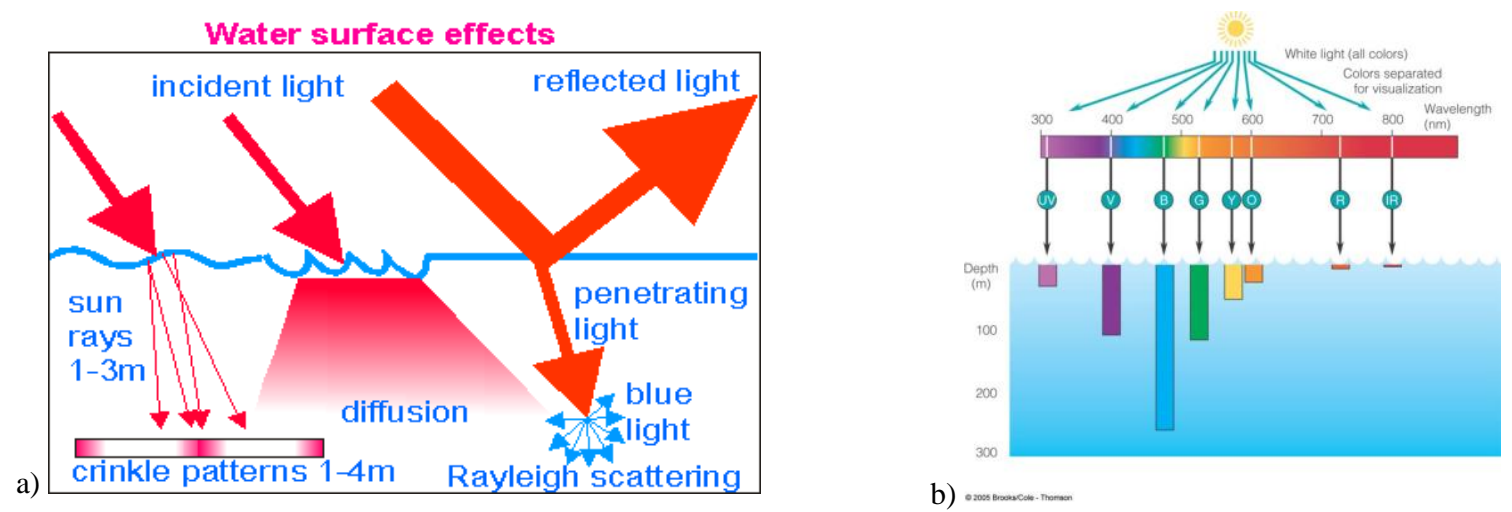

Figure 2. (a) Water surface effects on incident sunlight (Floor, 2005); (b) selective light absorption of colour (wavelength) in the open ocean (Kennesaw State University).

\section{PROPERTIES OF WATER AND THEIR INFLUENCE ON UNDERWATER PHOTOGRAPHY AND PHOTOGRAMMETRY}

Water is a medium inherently different from air and the first essential difference resides in the medium density. Seawater is nearly 800 times denser than air, and this influences the image formation underwater altering the path of optical rays. Density of seawater is not constant through the depth, being a function of temperature, salinity and pressure (Fig. 1a). These quantities are all correlated: density increases as temperature decreases, salinity increases as pressure increases, pressure increases linearly with depth (every $10 \mathrm{~m}$ the pressure increases of 1 atmosphere, equal to $1.033 \mathrm{~N} / \mathrm{cm} 2$ ). It is fundamental to properly consider the effect of pressure. Although this factor is extremely critical for very deep underwater inspections (see Fig. $1 b)$, pressure variation with depth affects any underwater optical system at whatever depth. Internal arrangement may be altered and subjected to changes as the working depth varies.

Other optical phenomena are to be accounted for underwater, all related to the so called inherent optical properties that govern propagation of light in water.

\subsection{Light absorption}

When sunlight reaches the sea surface, the great amount of the radiation penetrates and it is absorbed almost the $94 \%$ in open ocean, source National Snow and Ice Data Centre - NSIDC), little is reflected. The amount of light that is reflected upward depends strongly on the height of the sun (place on Earth, time of day and season) and the condition of the sea. A rough sea absorbs more light whereas a mirror-like sea reflects more (Fig. 2a). Sunlight reflections casted by the sea surface should be firmly avoided for photogrammetric applications because they could affect the extraction of automatic interesting features, as well as produce poor quality object texture. Figure 3 shows the same scene with (a) and without (b) sunlight reflections. Water acts as a selective filter: the great amount of light entering the sea is absorbed (it is converted in heat) within the first meters; only $1 \%$ of light entering the sea reaches $100 \mathrm{~m}$. The different components of light, characterised by different wavelengths, are absorbed differently. Longer wavelengths in the visible spectrum (red, orange) together with UV are absorbed first, short wavelengths are absorbed last. The maximum penetration depth depends on water composition: in turbid coastal waters light rarely penetrates deeper than $20 \mathrm{~m}$; while in the open ocean blue light penetrates even more than $200 \mathrm{~m}$ (Fig. 2b) and after that depth there is almost no light.

To restore the full range of colours in marine environment, the use of artificial light source (strobes or flashes) is required. The use of artificial light source is also crucial to compensate for light attenuation due to the absorption that limits the visibility distance.

\subsection{Turbidity, scattering and backscattering}

Turbidity in water is due to suspended particles (phytoplankton, organic matter, pollution, etc.) that cause the light to be scattered. The more the particles, the higher the turbidity. Turbidity of water is generally quantified using the Secchi distance, an old and simple method introduced in 1865. A circular disk divided in four alternating sections, two white and two black, is immersed in water from a boat and the distance at which the disk is not more visible is defined as one Secchi distance.
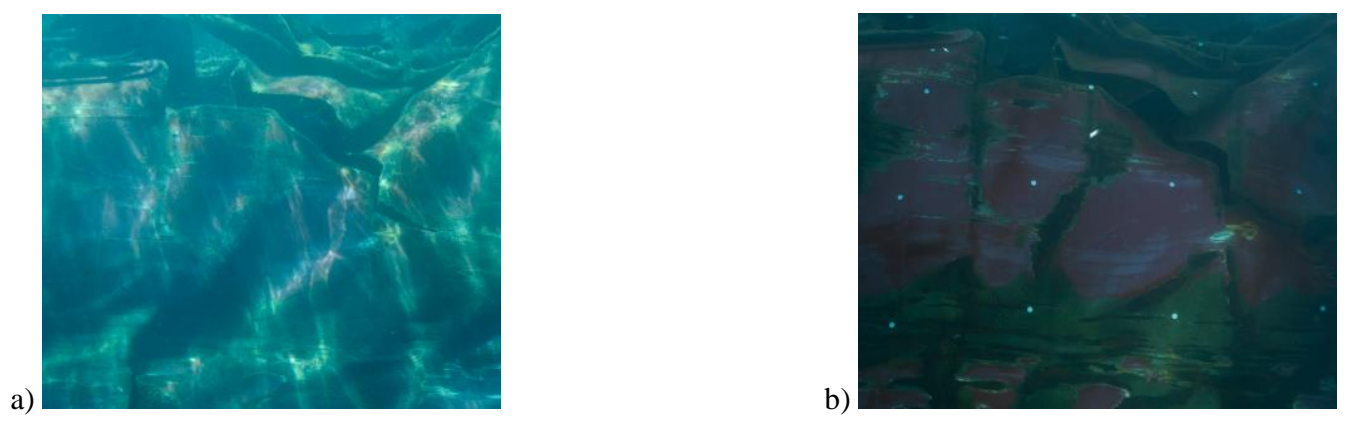

Figure 3. Effect of sunlight reflections: the two images show the same submerged area with (a) and without (b) reflections. 
a)

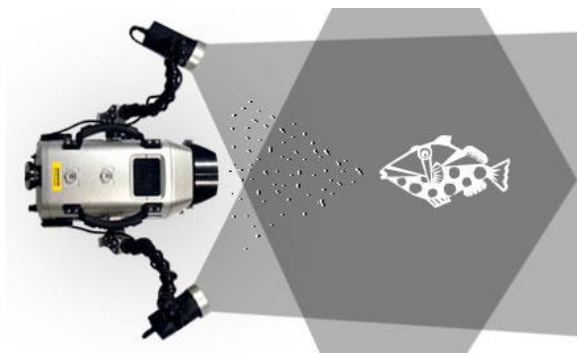

b)

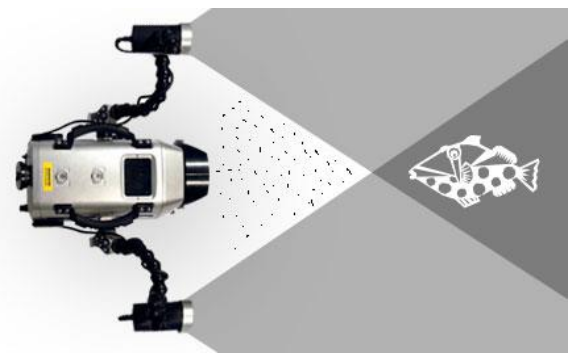

Figure 4. Backscattering: improper (a) and proper (b) position of strobe lights (Backscatter).

Scattering or diffuse reflection is an optical phenomenon that arises when the light rays are randomly deviated from their straight paths. Scattering limits image quality, reducing the contrast and producing blurred images.

When strobes are used, also backscattering can be introduced: it is similar to scattering with the difference that the light from the artificial source is reflected from the particles mainly back to the camera. To reduce backscattering, strobes should be carefully positioned, avoiding to point them directly to the subject (Fig. 4). The closer the flash to the camera, the more backscatter is produced. The closer to the subject the picture is taken, the less water and particles are present between the camera and subject, the less backscatter is produced.

As a consequence of the reported considerations, it is evident that taking photographs underwater is strictly conditioned by the medium characteristics, among which turbidity is the main limiting constraint. Moreover, scatter and backscatter reduce contrast of the scene and the final quality of the image. Considering the special lighting setup needed underwater, even in very clear water, yet the image acquisition can be difficult. Indeed when a Secchi distance corresponds to several meters a strong illumination would be required to light the object and a wider baseline would be necessary between the two lateral light sources. In these cases the system of cameras and strobe lights would require more than one diver.

\section{UNDERWATER PHOTOGRAPHY EQUIPMENT}

Since the first developments of photography it has been clear that to take pictures underwater proper equipment shall be used. The first underwater camera systems were developed by the French marine biologist Louis Boutan at the end of the nineteenth century. In the more compact and portable version (Figure 5a) the system incorporated two dual, electrical lamps for enhancing illumination thus reducing the exposure time. The breakthrough in underwater photography was represented in 1943 by the invention of the first open-circuit, self-contained underwater breathing apparatus (or "SCUBA"), which revolutionized the world of diving, and the development of pearliest portable underwater camera systems in the ' 50 , like the Rolleimarin underwater housing for the medium format professional twin-lens Rollei 6x6cm camera (Fig. 5b) and Nikon's Nikonos series cameras (Fig. 5c). In the 1970s, mainly pushed by Al Giddings, a worldwide renowned underwater cinematographer, the use of hemispherical dome ports, optimized for underwater and wide-angle optic, started to become more and more popular (Encyclopedia). At the end of the 1990s, the revolution brought by compact digital still cameras has marked irreversibly the world of photography, in general, and that of underwater photography, in particular. A variety of functional and fancy, professional and consumergrade waterproof housings has been released on the market for any type of digital cameras, featuring two types of lens port, flat and spherical (Fig. 5d-e-f).

\subsection{Flat and dome lens port}

Flat and hemispherical dome ports main characteristics are summarised in table 1 . As shown, they significantly differ from each other and influence the image acquisition and formation. The dissimilar effect and behaviour is due to their shapes: flat ports, being flat surfaces between two distinct media characterised by different refractive indices (i.e., water outside the waterproof housing and air inside) obeys to the Snell's law. As a consequence, the optical rays deviate from the original path, when pass through the flat port from the water to the camera-lens system inside the pressure housing, and are bent towards the port surface normal (refraction). On the contrary, hemispherical dome ports are composed by two spherical surfaces (external and internal), which theoretical should have the same centre of curvature. The dome port thickness is provided by the difference of radii of curvature of the two surfaces and should be manufactured as much uniform as possible. If the centre of lens (lens entrance pupil, EP, which also represents the perspective centre) is correctly placed in the ideally unique centre of the spherical surfaces, the light rays enter the dome port almost perpendicularly and go to the EP without refraction. In order to verify such conditions, the manufacture of dome port lenses should be highly accurate, thus being more demanding and expensive than the production of flat ports.

\subsection{Geometric and optical characterization of a hemispherical dome port}

In Menna et al. (2016), the geometric and optic characterization of the 7" NI320 dome port (Fig. 5f) produced by the Italian company NiMAR is presented. The work aims at understanding how deviations of the actual manufacturing from the ideal spherical and concentric shape of the dome surfaces would influence the optics of the system. A reverse engineering process of the dome is carried out, showing that the curvature centres of the outer and inner surfaces have a misalignment less than $1.5 \mathrm{~mm}$, with the maximum component along the optical axis equal to $7.7 \mathrm{~mm}$. The dome can be mounted on the NiMAR NI303D waterproof polycarbonate case (Fig. 5f) for Nikon D300 DSLR camera and is designed to work with different lenses whose focal length ranges from $20 \mathrm{~mm}$ to $35 \mathrm{~mm}$. With the possibility of using several focal lengths, it should be expected that the position of the EP will vary accordingly. 
a)

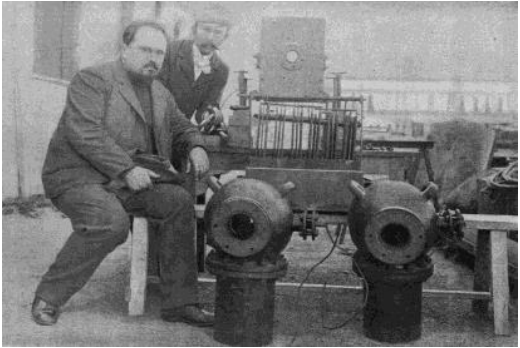

d)

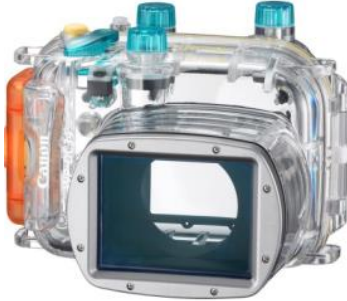

Figure 5. (a) Boutan's underwater camera (Fadedanblurred). (b) Rolleimarin underwater housing with flash (Pbase). (c) Nikonos Calypso camera with underwater electronic flash (frames extracted from EDC). (d-e-f) Waterproof housings for digital cameras; from left to right: Canon with flat port for compact cameras, Seacam and NiMAR with dome port for DSLR cameras.

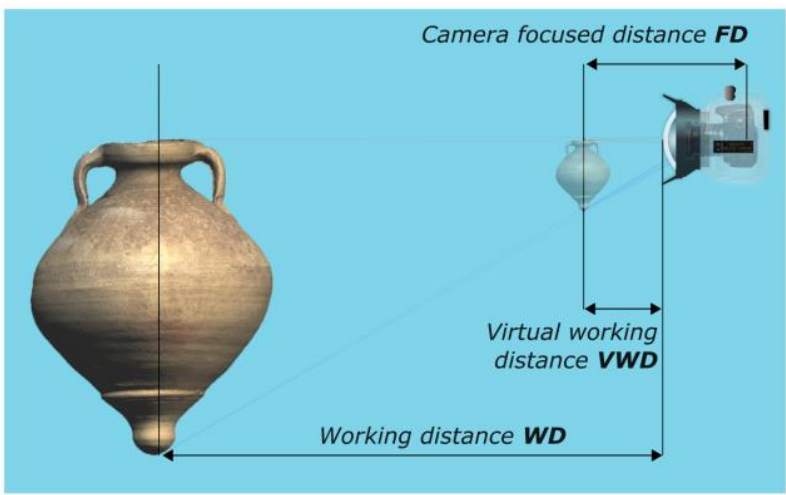

Figure 6. Effect of a dome port: a subject located at a working distance (WD) appears smaller and much closer to the camera virtual working distance (VWD).

An experimental investigation is realised to locate the EP inside the NI303D pressure case and with the respect to curvature centre of the NI320 dome port.

Two Nikkor lenses are tested, namely the $24 \mathrm{~mm}$ f/2. 8AF-D and $35 \mathrm{~mm}$ f $/ 2.0$ AF-D. The EP position results maximum $5.4 \mathrm{~mm}$ ahead of the curvature centre of the dome surfaces (i.e., closer to the dome), whit a misalignment in the plane perpendicular to the optical axis of about $1 \mathrm{~mm}$. Using the geometric data reported above, the optics of the investigated dome port is studied using the optical ray tracing software Winlens.

Table 2 shows the values of working distances (WD) from a real object point underwater versus its virtual image distance (or subject to entrance pupil distance DS2EP) from the entrance pupil (supposed to be placed in the dome centre). Virtual working distances (VWD), as defined in Figure 6, are also reported. Note that for simplicity the distances are reported positive. It is worth to note that the virtual image of a real object underwater is compressed in a very narrow virtual space just 20 $\mathrm{cm}$ deep in front of the dome glass. Moreover if the minimum focusing distances for the two Nikkor AF 24 and $35 \mathrm{~mm}$ lenses are considered, it results that the minimum working distances WD for the two lenses is respectively $-750 \mathrm{~mm}$ and $-300 \mathrm{~mm}$. For closer objects, additional close up lenses should be mounted to the front of the camera in order to produce sharp images.

\section{UNDERWATER AND IN-AIR SYSTEM CALIBRATION}

To investigate the influence of the dome port in real conditions, the camera system, which underwater comprises the camera + lens together with the pressure housing + lens port, is calibrated in a swimming pool. As in classical photogrammetry, calibration is fundamental to assure accurate and reliable measurements of 3D objects. Several algorithms and procedures have been proposed in literature for underwater camera calibration, both with flat and dome lens ports. All the different approaches fall into two main classes: (a) the ray tracing method which aims at rigorously and explicitly modelling the effect of refraction and any deviation from the ideal straight path described by light rays, and (b) the implicit absorption of the optical effects due to water and lens port adopting the standard pinhole camera model and a terrestrial-like self-calibration approach. A detailed and critical review on underwater camera calibration is out of the scope of this research work, but the interested readers can refer to Shortis (2015). The calibration method adopted in this investigation follows approach (b). Calibration of underwater camera system at the predominant working conditions would provide more accurate and reliable results. Moreover, dome ports should introduce little refraction effects that can be handled using a classical photogrammetric self-calibration approach. Two photogrammetric acquisitions for self-calibration are realized, one underwater and one in air. The camera with the $24 \mathrm{~mm}$ at $\mathrm{f} / 8.0$ is focused at $1 \mathrm{~m}$, setting fixed during the acquisition (autofocus disabled) to not change the interior orientation parameters. 


\begin{tabular}{|c|c|c|}
\hline & FLAT PORT & HEMISPHERICAL DOME PORT \\
\hline Description & $\begin{array}{l}\text { Flat plane of optically transparent glass or } \\
\text { plastic }\end{array}$ & $\begin{array}{l}\text { Concentric lens acting as additional optical element } \\
\text { (negative or diverging lens) }\end{array}$ \\
\hline $\begin{array}{l}\text { Field of view (FOV) WRT } \\
\text { the camera-lens system }\end{array}$ & Reduced & Equal \\
\hline $\begin{array}{l}\text { Focal length WRT the } \\
\text { camera-lens system }\end{array}$ & $\begin{array}{l}\text { Increased (by a factor equal to } \\
\text { approximately the ratio between the } \\
\text { refraction indices of water and air) }\end{array}$ & Equal \\
\hline $\begin{array}{l}\text { Magnification WRT the } \\
\text { camera-lens system }\end{array}$ & $\begin{array}{l}\text { Increased (by a factor equal to } \\
\text { approximately the ratio between the } \\
\text { refraction indices of water and air) }\end{array}$ & Equal \\
\hline $\begin{array}{l}\text { Effect on the observed } \\
\text { object }\end{array}$ & $\begin{array}{l}\text { The object appears closer to the camera by } \\
\text { a factor equal to approximately the ratio } \\
\text { between the refraction indices of water and } \\
\text { air. }\end{array}$ & $\begin{array}{l}\text { An upright, smaller virtual image of the object is } \\
\text { formed at a distance from the dome surface equal } \\
\text { to } 3 \text { times the curvature radius of the dome. The } \\
\text { camera-lens system focuses on this virtual image. }\end{array}$ \\
\hline Maximum FOV & Limited to $96^{\circ}$ & Not limited \\
\hline Lens distortion & Pincushion distortion & No significant distortion \\
\hline Other effects & Chromatic aberration & $\begin{array}{l}\text { - Increase of Depth of field (DOF) by a factor } \\
\text { equal to approximately the ratio between the } \\
\text { refraction indices of water and air. } \\
\text { - } \quad \text { Spherical aberration } \\
\text { - } \quad \text { Field curvature }\end{array}$ \\
\hline Costs & Cheaper & More expensive \\
\hline Typical use & For compact digital cameras & For DSLR cameras \\
\hline
\end{tabular}

Table 1. Characteristics of flat and dome ports.

\begin{tabular}{|l|l|l|l|l|l|l|l|l|l|l|}
\hline WD $(\mathbf{m m})$ & $\mathbf{2 0 0}$ & $\mathbf{3 0 0}$ & $\mathbf{4 0 0}$ & $\mathbf{5 0 0}$ & $\mathbf{7 5 0}$ & $\mathbf{1 0 0 0}$ & $\mathbf{3 0 0 0}$ & $\mathbf{5 0 0 0}$ & $\mathbf{1 0 0 0 0}$ & Infinity \\
\hline \hline DS2EP $(\mathrm{mm})$ & 164.1 & 184.9 & 199.7 & 210.8 & 229.4 & 240.8 & 269.7 & 276.8 & 282.5 & 288.5 \\
\hline VWD $(\mathrm{mm})$ & 80.8 & 101.6 & 116.4 & 127.5 & 146.1 & 157.5 & 186.4 & 193.5 & 199.2 & 205.2 \\
\hline
\end{tabular}

Table 2. Real object distance versus its virtual image underwater for the NiMAR NI320 dome port.

Between the two calibrations, the camera is not removed from the pressure housing to keep the system stable as much as possible. An ad-hoc underwater test-field made of a planar aluminium board with resolution and photogrammetric coded targets is used (Fig. 7) both underwater in the pool and for calibration in air. Table 3 reports the camera calibration parameters obtained from the two calibrations. As shown in Figure 8 , the lens displays quite a pronounced barrel radial distortion both in air (red) and in water (blue). As previously anticipated by the reverse engineering of the dome, the advanced position of the entrance pupil of the lens respect to the dome centre introduces a small pincushion compensation effect resulting in a less negative overall distortion (less barrel). A significant variation in the principal distance between in air and underwater calibrations is also observed. This change is expected as the closer is the lens to the dome surface, the less spherical is the portion of the surface of the dome the camera looks trough. The extreme limit is when the lens front is very close to the dome inner surface and the entrance pupil is much more ahead than in the case study of this paper: in this case the dome portion in the field of view of the camera approaches the one of a flat port with a consequent increase of the principal distance by a factor of about 1.33 as reported in Table 1 .

Decentring distortion is introduced, due to the offset in the plane perpendicular to the optical axis between lens entrance pupil and dome surface centre. In air the decentring distortion parameters are not statistically significant thus are not adjusted for. As it can be observed in the graph, its magnitude in water is anyway very small compared to the radial component, as expected due to the smaller in-plane than along the axis misalignment. The in-plane offset can also explain the difference in the coordinates of the principal points. Figure 9 shows the difference between distortion maps in air and in water. a)

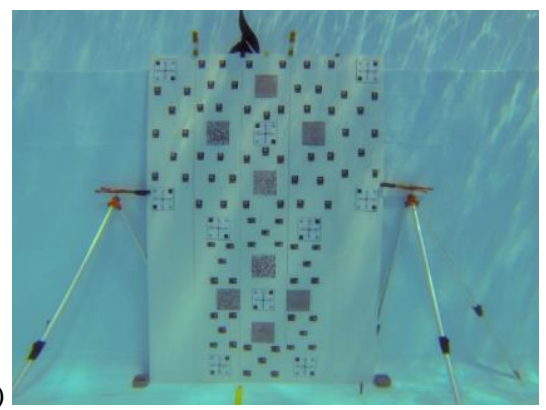

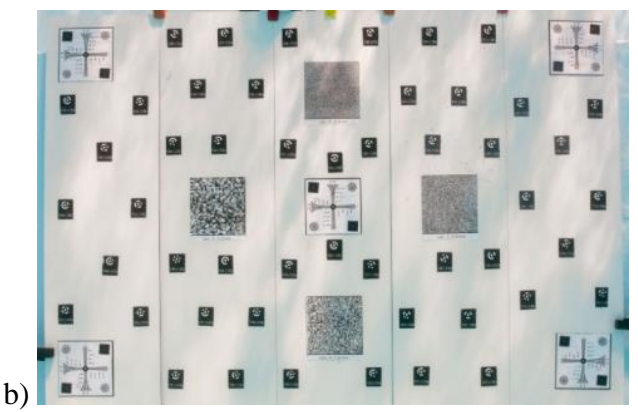

Figure 7. Test-field used in the swimming pool with stand with resolution and photogrammetric targets. 


\begin{tabular}{|l|l|l|l|l|}
\hline \multirow{2}{*}{ Camera Calibration Parameters } & \multicolumn{2}{|c|}{ AIR } & \multicolumn{2}{c|}{ UW } \\
\cline { 2 - 5 } & \multicolumn{1}{|c|}{ value } & \multicolumn{1}{c|}{ std. dev. } & \multicolumn{1}{c|}{ value } & std. dev. \\
\hline Principal distance $(\mathrm{mm})$ & 25.801 & 0.006 & 26.208 & 0.002 \\
\hline Principal Point $\mathrm{x}_{0}(\mathrm{~mm})$ & -0.026 & 0.002 & -0.058 & 0.003 \\
\hline Principal Point $\mathrm{y}_{0}(\mathrm{~mm})$ & -0.144 & 0.003 & -0.207 & 0.002 \\
\hline $\mathrm{K}_{1}$ & $1.842 \mathrm{e}-004$ & $1.2 \mathrm{e}-006$ & $1.663 \mathrm{e}-004$ & $6.1 \mathrm{e}-007$ \\
\hline $\mathrm{K}_{2}$ & $-3.030 \mathrm{e}-007$ & $7.4 \mathrm{e}-009$ & $-2.582 \mathrm{e}-007$ & $3.4 \mathrm{e}-009$ \\
\hline $\mathrm{K}_{3}$ & - & - & - & - \\
\hline $\mathrm{P}_{1}$ & - & - & $6.582 \mathrm{e}-006$ & $1.2 \mathrm{e}-006$ \\
\hline $\mathrm{P}_{2}$ & - & - & $1.620 \mathrm{e}-005$ & $8.7 \mathrm{e}-007$ \\
\hline
\end{tabular}

Table 3. Comparison between camera calibration in water (UW) and in air. Only statistically significant additional parameters are computed.

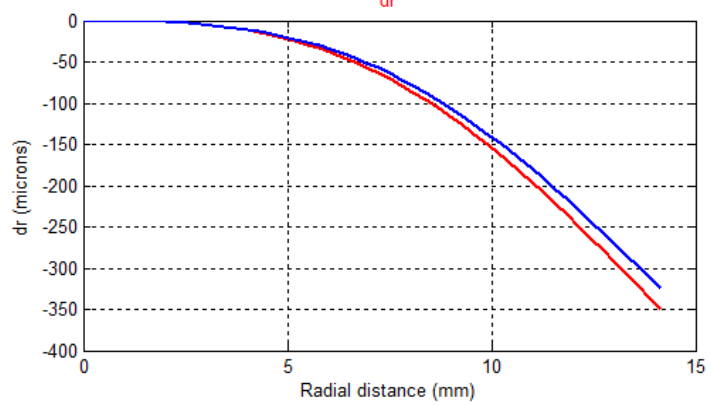

a)

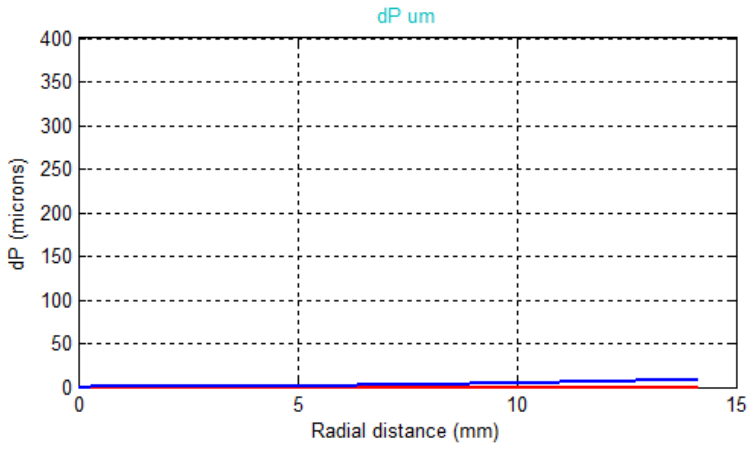
blue to the camera calibration underwater.
A distortion map displays according to a colour scale map the difference between the ideal pixel position (no distortion) and the actual pixel position due to the influence of radial and decentring distortions determined through camera calibration. As depicted in the figure and expected, the maximum difference is reached at the borders, whose magnitude is comparable with the differences highlighted in the distortion curves. An asymmetric behaviour can be also observed, likely due to the small in-plane misalignment between the lens entrance pupil and dome surface centre of curvature, slightly bigger along the $\mathrm{Y}$ axis.

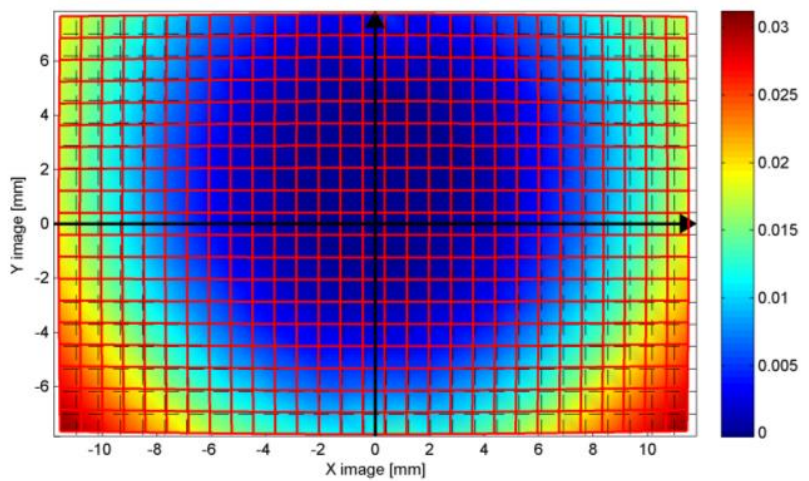

Figure 9. Difference between in air and in water distortion maps.

\section{INFLUENCE OF CALIBRATION PARAMETERS ON UNDERWATER 3D OBJECT RECOSTRUCTION}

The previous sections have shown that misalignment between dome port centre and lens EP modifies the lens distortion and, in particular, can introduce a decentring component. While up to now the investigation has been concentrated in image space, the aim of the following analysis is to expand the results in object space. In particular, the study aims at understanding if neglecting the decentring distortion produces relevant deformation in the reconstructed object. In the followings, two peculiar case studies are presented: the first experiment is designed to resemble a typical cultural heritage acquisition, with a small object surveyed at a big image scale with a circular and closed camera network; the second case involves the acquisition of an elongated body, surveyed with an aerial-like camera network with the inclusion of convergent images.

\subsection{Ancient amphora - circular camera network}

The ancient amphora (height $\approx 50 \mathrm{~cm}$ ) shown in Figure $10 \mathrm{a}$ is employed as test object and is measured and reconstructed both in air and underwater. The acquisition in air, considered the reference or ground truth to verify the underwater results, is carried out using a DSLR Nikon D750 camera with a $50 \mathrm{~mm}$ lens and a ground sample distance (GSD) of about $0.1 \mathrm{~mm}$. The system used underwater is the NiMAR pressure housing with dome lens port and the Nikon D300 with $24 \mathrm{~mm}$ lens presented before. The acquisition of the amphora is realised in the pool immediately after (Fig. 10b), in the same environmental conditions and camera settings (i.e., fixed focusing distance) of the underwater calibration (Section 4), obtaining a GSD of about $0.3 \mathrm{~mm}$.

Different calibration procedures for the underwater acquisition are tested and verified against the reference object:

a. Full pre-calibration: the images are oriented using as camera calibration parameters the full set (Table 3 ) derived from the underwater system calibration presented in Section 4.

b.Pre-calibration with only radial distortion: the images are oriented using another set of parameters derived from the underwater calibration, solving only for radial distortion.

c. Structure from motion (SfM) self-calibration: a selfcalibrating bundle adjustment is performed to estimate in 
one-step solution both camera calibration parameters with only radial distortion and image orientation.

The dense image matching is performed both for the reference and three underwater calibration approaches at $1 / 4$ of the original image resolution (i.e., double of the original GSD). From the dense point clouds, polygonal mesh models are generated with a mean spatial resolution of $0.5 \mathrm{~mm}$. Figure $11 \mathrm{a}$ and Figure $11 \mathrm{~b}$ show a detail of the in-air reference model and underwater calibration procedure (a). The comparisons with the reference model do not highlight either significant deformation in the geometry or substantial differences between the different underwater calibration approaches. As an example, the differences between the in-air model and the model from method (a) and (c) are shown in Figure 11c and Figure 11d, respectively. In all the cases $95 \%$ of differences are within \pm 0.5 $\mathrm{mm}$

\subsection{Elongated ship gash - aerial-like camera network}

In 2012, the Italian cruise ships "Costa Concordia" partially sunk off the coast of a small island in the Mediterranean Sea after the collision against a rock. The produced $60 \mathrm{~m}$ long gash was situated on the above-the-water side of the stranded ship and extended at the current waterline $4 \mathrm{~m}$ above and $4 \mathrm{~m}$ below the sea surface. The technique developed for surveying and modelling the ship part interested by the collision (Fig. 12a) is detailed presented in previous works (Menna et al., 2013; Nocerino, 2015). Here, the analysis is focused on the underwater camera calibration and its influence in object space when an elongated object is measured. For the Costa Concordia, the same underwater camera system under investigation (NiMAR pressure housing with dome lens port and the Nikon D300 with $24 \mathrm{~mm}$ lens) is used and also in this case, decentring distortion parameters are statistically significant. About 800 underwater images are taken according to a photogrammetric aerial-like strip scheme, with 4 overlapping strips at different depths, assuring a forward overlap of ca. $80 \%$ along strip and a sidelap of ca. $40 \%$ between two adjacent strips. Convergent images are also included in the camera network. The mean object distance is $3 \mathrm{~m}$, providing a GSD of about $0.7 \mathrm{~mm}$. The underwater mesh in Figure $12 \mathrm{a}$ is obtained including the decentring distortion. To show the influence of neglecting decentring component in the bundle adjustment, in Figure $12 \mathrm{~b}$ the Euclidean distances in meters for the processing with and without decentring distortion parameters are presented as colour map. The differences reach a maximum value of about $6 \mathrm{~cm}$.

\section{CONCLUSIONS}

Despite being more complex to build and assemble to camera pressure housings when compared to flat ports, dome ports show numerous advantages from a photogrammetric point of view as they preserve the main geometrical characteristics that rule the image formation. As far as the photogrammetric planning is concerned when using such ports it is fundamental to consider the variation in the focusing distance, modified due to the projection of a virtual image right in front of the port surface. A pre-defined focusing distance cannot be easily established if not using optical simulation software such as Winlens and particular care must be taken to avoid blurred images due to out of focus issues. The paper presented both from a theoretical point of view and from field experiments that the focal length (hence the field of view), the principal point position and the radial and decentring distortions are all preserved if the dome port and camera housing are properly manufactured and aligned. Misalignments in the order of few millimetres between the dome port and lens entrance pupil as well as difference between the inner and outer radii of the spherical surfaces of the dome do not produce departures from the geometrical model used in standard photogrammetry. The two case studies presented showed that the choice of the proper set of calibration parameters must be driven by the application of interest. For example, few pixels of maximum decentring distortion can be negligible for simple modelling tasks where the accuracy is not of primary importance while this is not the case when large objects are to be reconstructed. The archaeological case study represented by the amphora showed that the small maximum magnitude of decentring distortion do not produce statistically significant differences in the generated 3D models if they are not accounted for during camera calibration. On the contrary, for more complex case studies such as the one of the $60 \mathrm{~m}$ long Costa Concordia gash, the inclusion or exclusion of decentring distortion parameters produces relative differences as high as $6 \mathrm{~cm}$.

\section{ACKNOWLEDGEMENTS}

The authors thanks NiMAR which supported this research by providing photographic underwater equipment and useful insights about pressure housings manufacturing techniques.

\section{REFERENCES}

Backscatter,

http://www.backscatter.com/learn/article/article.php?ID=15

EDC, The Edgerton Digital Collections project, http://edgertondigital-collections.org/videos/hee-fv-019

Encyclopedia,

http://encyclopedia.jrank.org/articles/pages/1193/UnderwaterPhotography.html

Fadedanblurred, http://fadedandblurred.com/articles/the-worldsfirst-underwater-photographer-louis-boutan

Floor, J. A., 2005. Water and Light in Underwater Photography. http://www.seafriends.org.nz/phgraph/water.htm

Kennesaw State University, http://science.kennesaw.edu/ jdirnber/ BioOceanography/Lectures/LecPhysicalOcean/LecPhysicalOcean.h tml

Menna, F., Nocerino, E., Troisi, S. and Remondino, F., 2013. A photogrammetric approach to survey floating and semi-submerged objects. SPIE Optical Metrology, Vol. 8791, pp. 87910H-87910H

Menna, F., Nocerino, E., Fassi, F. and Remondino, F., 2016. Geometric and optic characterization of a hemispherical dome port for underwater photogrammetry. Sensors, Vol. 16(1), 48

NiMAR S.r.l., http://www.nimar.it/

Nocerino, E., 2015. A full photogrammetric approach for surveying semi-submerged and floating objects. $\mathrm{PhD}$ thesis.

Ocean Stanford Edu, ocean.stanford.edu/bomc/chem/lecture_03.pdf Qioptiq Photonics, http://www.qioptiq.com/

Pbase, http://www.pbase.com/image/64660924

Shortis, M., 2015. Calibration techniques for accurate measurements by underwater camera systems. Sensors, 15(12), pp.30810-30826

Shortis, M., Harvey, E. and Seager, J., 2007. A review of the status and trends in underwater videometric measurement. SPIE Vol. 6491, pp. 1-26 
The International Archives of the Photogrammetry, Remote Sensing and Spatial Information Sciences, Volume XL-3/W4, 2016

EuroCOW 2016, the European Calibration and Orientation Workshop, 10-12 Feb 2016, Lausanne, Switzerland

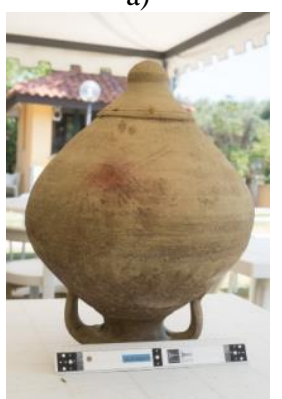

b)

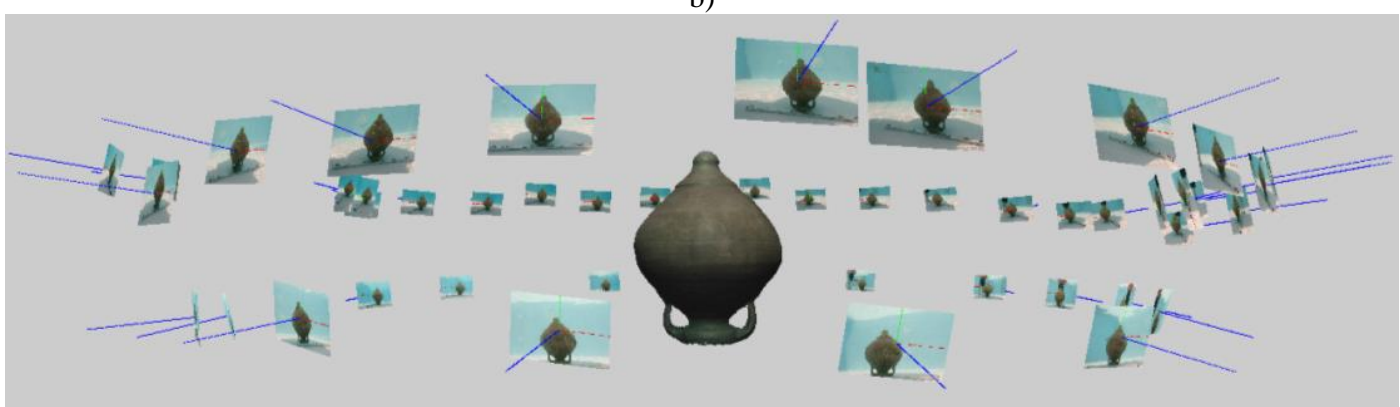

Figure 10. (a) Test object (amphora) pictured in air. (b) Underwater camera network.

a)

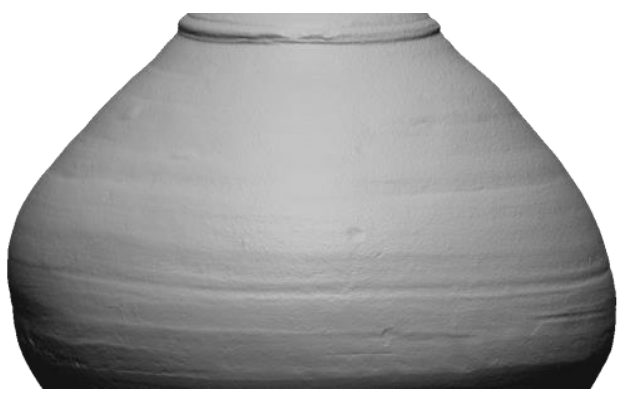

c)

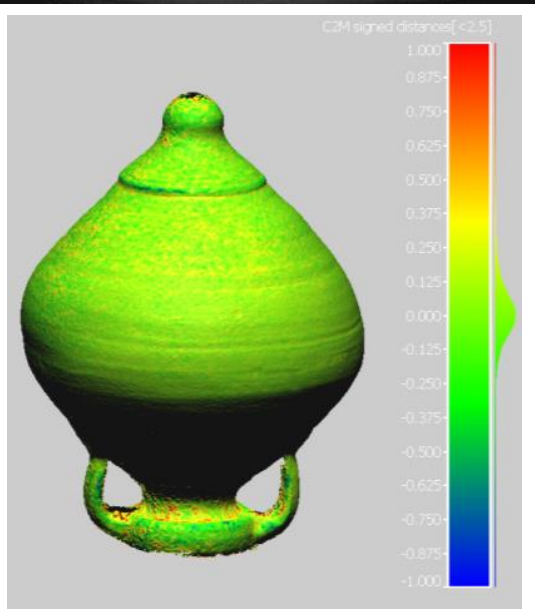

b)

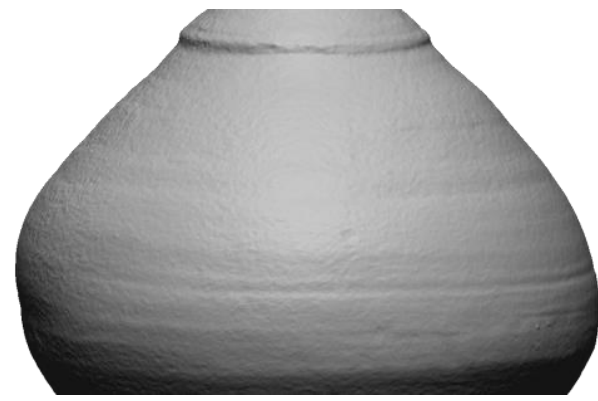

d)

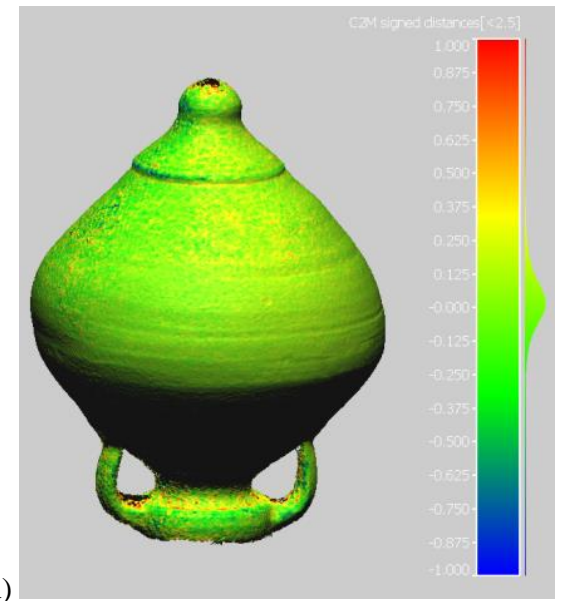

Figure 11. Particular of reference (a) and underwater (b) mesh model. Colour maps of Euclidean distances [mm] between the reference model and the one obtained with the underwater calibration approach a (c) and the underwater calibration approach $\mathrm{c}(\mathrm{d})$.

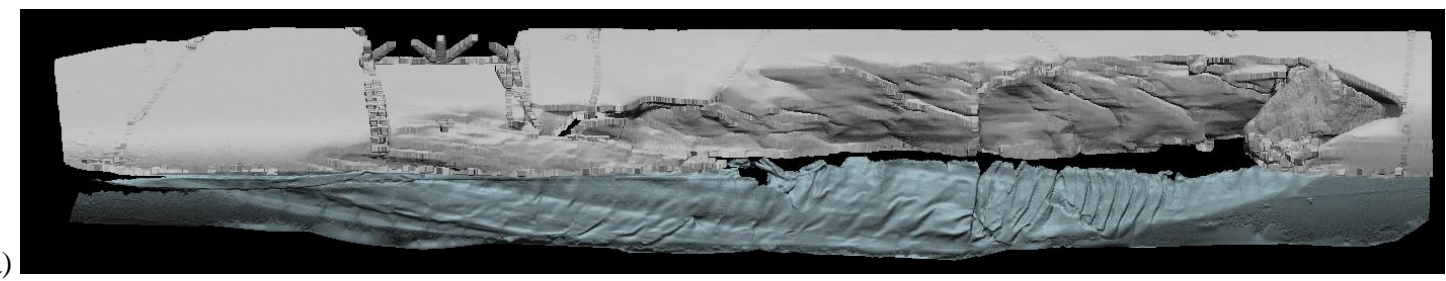

b)
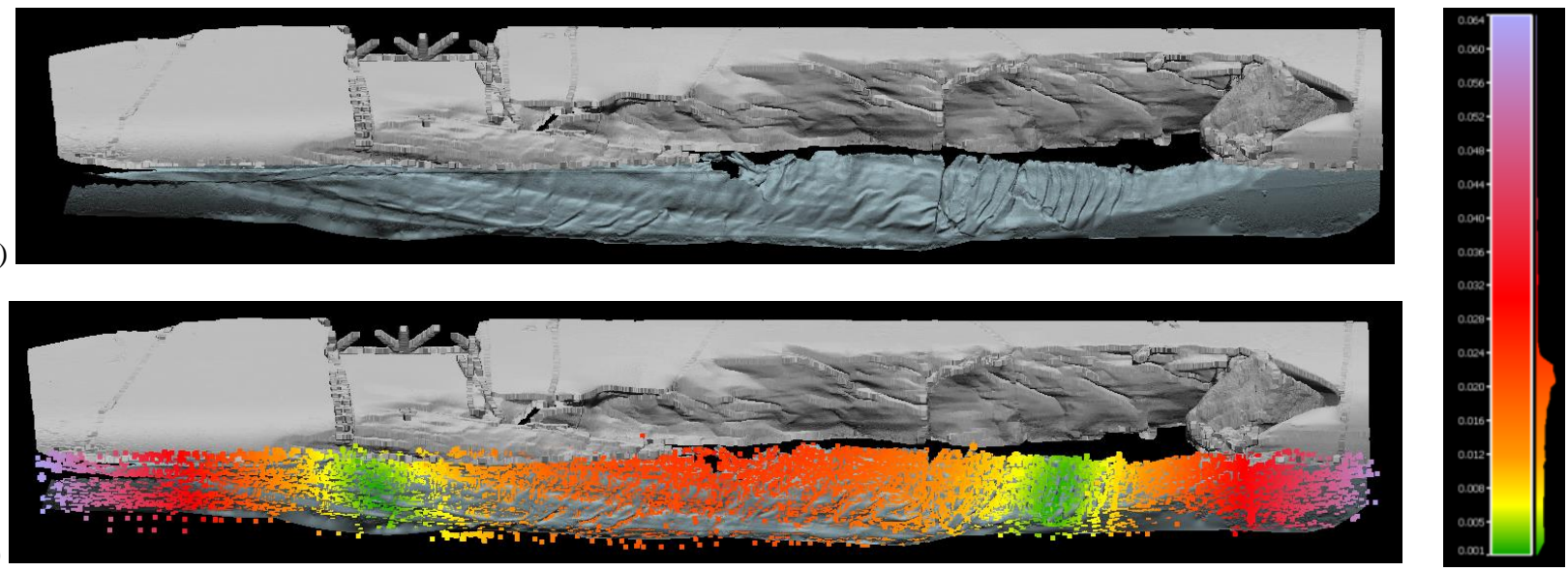

[m]

Figure 12. (a) Mesh model of the Costa Concordia gash. (b) Colour maps of Euclidean distances [m] between tie points of the underwater part with and without decentring distortion parameters. 